\title{
Child and Parental Mental Health as Correlates of School Non-Attendance and School Refusal in Children on the Autism Spectrum
}

\author{
Dawn Adams ${ }^{1,2}$ (D) \\ Accepted: 19 July 2021 / Published online: 30 July 2021 \\ (c) The Author(s), under exclusive licence to Springer Science+Business Media, LLC, part of Springer Nature 2021
}

\begin{abstract}
Children on the autism spectrum miss more school than their peers, but limited work has explored why this may be. This study aimed to document the frequency at which children on the autism spectrum miss half and full days of school and the reasons for these absences. Parents of 106 school-aged children on the autism spectrum completed online questionnaires on rates of school non-attendance, family factors, child anxiety, and parental mental health. On average across a four week period, children missed 6 full days of school. The most common reason for full-day absences was school refusal and for half-day absences was medical/therapy appointments. Parental employment status, increased child age, child anxiety, and differing aspects of parental mental health were identified as correlates of specific subtypes of school non-attendance.
\end{abstract}

Keywords Absenteeism $\cdot$ Absence $\cdot$ School refusal $\cdot$ Anxiety $\cdot$ Stress $\cdot$ Education

\section{Introduction}

Children on the autism spectrum have been shown to underperform academically compared to their peers, yet no consistent predictors of this academic underachievement have been identified (Keen et al., 2016). It may be that a wide range of possibly interacting factors may contribute (at least partially) to this academic underachievement, including cognitive ability (e.g. Milgramm et al., 2021), working memory (Mayes et al., 2020), executive functioning (St John et al., 2018) and academic enablers (Keen et al., 2021). One factor that is strongly associated with academic underachievement in the general student population is school non-attendance (Filippello et al., 2019; Ingul et al., 2019). School non-attendance can occur for many reasons. In the general student literature, reasons for school non-attendance are classified into two forms: "problematic absenteeism",

Dawn Adams

dawn.adams@griffith.edu.au

1 Autism Centre of Excellence, School of Education and Professional Studies, Griffith University, Messines Ridge Road, Mt Gravatt, Brisbane, QLD 4122, Australia

2 Griffith Institute of Educational Research, Griffith University, Brisbane, Australia which includes truancy, exclusions, parent withdrawals, and "non-problematic absenteeism", which describes absences due to medical appointments or family/cultural observances. International estimates of school non-attendance rates across all students suggest that students miss 5-7\% of school (Australian Institute of Health \& Welfare, 2020; Department for Education, 2019). In the only paper to date to look at a broad range of both "problematic" and "non-problematic" forms of school non-attendance in children on the autism spectrum, Totsika et al. (2020) reported that students on the autism spectrum miss $22 \%$ of school.

Despite this high prevalence of school non-attendance and its potentially long-lasting impacts on the lives of people on the autism spectrum, research into school non-attendance in autism is scant. After reporting upon the prevalence of school non-attendance in children on the autism spectrum, Totsika et al. (2020) used the Kids and Teens at School framework (KiTeS; Melvin et al., 2019), which is based upon an ecological systems perspective, to explore potential factors and correlates of school non-attendance in their sample of 486 children on the autism spectrum. Regardless of how they explored school non-attendance (number of days missed, whether the student missed more than $10 \%$ of days, school absence on any given day), the same four variables were associated with increased risk of non-attendance: attending a mainstream school, parental unemployment, 
increasing child age, and not living in a two-parent household. These variables align with potential risk factors and predictors for school absenteeism in typically developing students, with a recent meta-analysis (Gubbels et al., 2019) identifying increasing child age, parental unemployment, lower IQ than peers/learning difficulties, and non-nuclear family structure as significant predictors of absenteeism with a small or medium effect size. However, while there may be some overlap in the predictive factors, there is a striking difference in the body of work which has evaluated the potential factors. Gubbels et al.'s (2019) meta-analysis of factors predicting school non-attendance in typically developing students drew data from 43 studies to identify 32 significant predictors. In contrast, the Totsika et al. study is, at present, the only study to explore predictors of a broad range of both "problematic" and "non-problematic" forms of school non-attendance in students on the autism spectrum, and it identified four significant predictors. This suggests that there is a large number of variables, including child and family mental health, yet to be explored in relation to school nonattendance in students on the autism spectrum and highlights the critical need for further work and research in this area.

\section{Types of School Non-Attendance}

Summarised in Heyne et al. (2019), the suggestion of differentiating between different forms of school non-attendance goes back as far as 1932. This early suggestion has since been supported by empirical research identifying that child (e.g., internalising and externalising behaviours) as well as family and school factors are associated with different types of non-attendance (for a review see Heyne et al., 2019). In order to screen and differentiate across different types of school non-attendance, Heyne et al. proposed the School Non-Attendance ChecKlist (SNACK). This asks parents to report on the number of days of school missed in the last four weeks across 14 possible reasons. Through using the SNACK, Totsika et al. (2020) identified that the most frequent cause of school non-attendance in students on the autism spectrum was school reluctance/refusal, accounting for $43 \%$ of absences. "Non-problematic" absences (e.g., medical appointments) were also common, accounting for $32 \%$ of all absences. As children on the autism spectrum experience higher levels of physical and mental health difficulties than their age-matched typically developing peers (Fortuna et al., 2016), they are more likely to attend general practitioner or outpatient healthcare visits (Weiss et al., 2018; Zerbo et al., 2019) which then likely contributes to this high number of absences due to medical appointments.

Although school refusal accounts for nearly half of the absences in students on the autism spectrum, only four studies (in addition to Totsika et al., 2020, discussed above) have specifically focussed upon the factors which impact or predict higher school refusal in autism. Two of these (Bitsika et al., 2020; McClemont et al., 2020) focussed solely on school refusal that was due to bullying (i.e. Bitsika et al. asked parents whether their child had "asked their parents if they could stay home from school the next day because of being bullied" and McClermont et al. asked "Has your child ever refused school due to bullying"). Ochi et al. (2020) also explored bullying in relation to school refusal. In their sample, bullying was the only significant predictive factor for school refusal in boys, whereas for girls the risk of school refusal was further increased with maladjustment at the time of school entrance and physical symptoms. Other factors including parent rated friendship skills, concerns about the course, problems with school regulations and discord at home were not identified as predictive of school refusal for either gender. The impact of a student's cognitive profile and academic skills was highlighted in Munkhaugen et al. (2019) who reported lower social motivation, specific aspects of executive functioning, and internalising symptoms as risk factors for school refusal. However, other factors such as social communication, externalising problems and attentional problems were not identified as risk factors in their sample of 62 students aged 9-16 years, all of whom were in inclusive educational settings. Initial explorations of measures of school refusal designed for the general student population indicate that the factor structure established in typically-developing students is not valid in students on the autism spectrum, suggesting that other or additional factors may be influencing school refusal in children on the spectrum (Adams et al., 2021).

Similarly to school refusal, there has been recent research interest in school exclusion for students on the autism spectrum. This has been predominantly qualitative, with the experiences both the students (e.g. Brede et al., 2017) and their parents (Sproston et al., 2017) being documented. However, there has been little exploration of factors which might be predictive of or contributing the elevated level of school exclusions reported in students on the autism spectrum (Krezmien et al., 2017), highlighting this as an area for future research.

In summary, school non-attendance is three times higher amongst children on the autism spectrum than for typically developing children, which likely contributes to the significant underachievement reported in those on the spectrum. Only one study to data has looked at multiple forms of school non-attendance in autism specifically. That one study (Totsika et al., 2020) plus the small number of studies focusing upon school refusal and school exclusion all highlight the importance of considering child, family, and school factors from across the KiTeS framework as predictors of school non-attendance, and of exploring the possibility of differing factors predicting different types of school non-attendance. There is therefore a clear and 
pressing need for research which explores a broad range of both "problematic" and "non-problematic" forms of school non-attendance and builds upon the range of child, family, and school factors identified as predictors. Identifying the factors associated with school non-attendance is important as it potentially identifies avenues for intervention or even prevention.

\section{The Potential Role of Parent and Child Mental Health on School Non-Attendance}

One factor that meta-analyses have identified as predictive of school non-attendance in typically developing children is child anxiety (Gubbels et al., 2019). Despite anxiety being up to six times more common in children on the autism spectrum than in typically developing children (van Steensel et al., 2011), and self-report and parent-report studies suggesting that more than $70 \%$ of children on the autism spectrum are impacted by anxiety at school (Adams et al., 2018; Adams et al., 2019d), a systematic review highlighted that anxiety about school or anxiety when at school has received very little attention for children on the autism spectrum (Adams et al., 2019c). Specific aspects of anxiety have been shown to impact upon educational quality of life over and above autism characteristics (Adams et al., 2019a; 2019b) and both children on the autism spectrum and their parents rate anxiety as having a significant impact on classroom performance and time with friends at break or lunch (den Houting et al., 2020. There is therefore good evidence to suggest that anxiety impacts multiple aspects of school and that anxiety should therefore be explored as a potential correlate of school non-attendance in this population.

Child anxiety is associated with parental anxiety and mental health (Adams \& Emerson, 2020a), a factor that has been shown to be predictive of both emerging and established school refusal in typically developing children (e.g., Egger et al., 2003). Despite this, and the established finding that mental health challenges are higher in parents of children on the autism spectrum than in their typically developing peers, parental mental health has also not been explored in relation to school non-attendance in children on the autism spectrum. Given that both child and parental anxiety are modifiable through intervention (e.g., Da Paz \& Wallander, 2017; Perihan et al., 2020), these would seem important and potentially impactful factors to explore.

The aims of this study were therefore to (a) document the prevalence of, and reasons for, half and full days of school non-attendance in students on the autism spectrum; (b) explore whether previously identified factors predict the rate of school non-attendance in this sample; and (c) identify whether parent or child mental health predicts school nonattendance in students on the autism spectrum.

\section{Method}

Ethical clearance for this study was granted through the Griffith University Human Research Ethics Committee, approval number 2019/462.

\section{Recruitment Procedures}

Parents of children on the autism spectrum were recruited through research centre social media posts which were shared by 79 individuals and organisations, creating a snowballing effect. The information sheet, consent form, and questionnaire were all online. Parents could complete the questions over multiple sittings if they desired and could close the questionnaire at any time should they wish to stop participating. In total, 155 parents began the questionnaire; 27 were excluded as their score on the Social Communication Questionnaire (SCQ; Rutter et al., 2003) was below the cut-off of 15 or their SCQ questionnaire administered as part of the questionnaire pack was incomplete and 22 were excluded as either they did not go beyond the demographics page to complete the questionnaires of interest to this study, or the child they were reporting on was aged above 17 years (the age at which mandatory schooling ends in Australia). All data collection happened prior to the COVID-19 pandemic.

\section{Participants}

After exclusions, the sample consisted of data from parents of 106 children on the autism spectrum enrolled in (but not necessarily attending) full-time education. The sample were predominantly parents of boys $(n=71 ; 67 \%)$ with a mean age of 11.8 years (SD 3.1 years). All but six children lived full-time with the parent completing the questionnaire. The six children who did not live with that parent full-time had shared parental custody arrangements but lived with the parent completing the questionnaire for at least half of the week. Demographic information for the children is presented in Table 1. Parent informants were predominantly mothers ( $n=94,88.7 \%$ ), with those remaining stating they were the child's father $(n=4)$, carer $(n=2)$, or parent $(n=6)$.

\section{Measures}

\section{Demographic Characteristics}

Demographic characteristics were collected using a parent questionnaire focusing upon child (age, gender, diagnoses), parent (education, employment), and household (income) variables. Responses were recoded for educational setting 
Table 1 Child and parent demographics based upon parent report $(\mathrm{N}=106)$

\begin{tabular}{|c|c|c|c|}
\hline & & $N$ & $\%$ \\
\hline \multicolumn{4}{|l|}{ Child demographics } \\
\hline Gender of child & Male & 71 & 67 \\
\hline \multirow[t]{2}{*}{ School enrolled into } & Mainstream & 90 & 85 \\
\hline & Special/specialist & 16 & 15 \\
\hline \multirow[t]{6}{*}{ Formally diagnosed co-occurring diagnoses } & Anxiety & 69 & 65 \\
\hline & Depression & 14 & 13 \\
\hline & ADHD/ADD & 44 & 42 \\
\hline & Motor difficulties/Dyspraxia & 11 & 10 \\
\hline & Speech and language disorder & 22 & 21 \\
\hline & Intellectual disability & 12 & 11 \\
\hline \multicolumn{4}{|l|}{ Caregiver and family demographics } \\
\hline Relationship to child & Mother & 94 & 89 \\
\hline \multirow[t]{5}{*}{ Age group } & Up to 30 years & 3 & 3 \\
\hline & $31-40$ years & 37 & 35 \\
\hline & $41-50$ years & 58 & 54 \\
\hline & 51 years or older & 7 & 7 \\
\hline & Did not wish to disclose age & 1 & 1 \\
\hline \multirow[t]{2}{*}{ Parent self-reported diagnoses (lifetime) } & Mental health disorder & 36 & 34 \\
\hline & Autism & 7 & 7 \\
\hline Education level & Tertiary level & 82 & 7 \\
\hline \multirow[t]{2}{*}{ Parent employment status } & In paid employment & 57 & 54 \\
\hline & $\begin{array}{l}\text { Unemployed/studying/not in paid } \\
\text { employment }\end{array}$ & 49 & 46 \\
\hline \multirow[t]{5}{*}{ Family income (AUD\$) } & Below $\$ 37,000$ & 19 & 18 \\
\hline & $\$ 37,001-\$ 80,000$ & 23 & 22 \\
\hline & $\$ 80,001-\$ 180,000$ & 40 & 38 \\
\hline & $\$ 180,001$ or above & 18 & 17 \\
\hline & Did not wish to disclose & 6 & 6 \\
\hline
\end{tabular}

(mainstream/special or specialist setting), income (above/ below the Australian median family income), and parental employment status (paid employment/unemployed, volunteering or studying) for the purpose of analysis.

\section{Autism Characteristics}

The SCQ (Lifetime version; Rutter et al., 2003) was used in this study to provide verification of parent-reported autism diagnosis. The SCQ consists of 40 yes/no questions which ask parents about behaviours that may be indicative of social, communicative, or stereotyped behaviours associated on the autism spectrum. A recent meta-analysis (Chesnut et al., 2017) concluded that with the cut-off score of 15 , the area under the receiver operating characteristic curve is 0.89 , making it an acceptable screening measure. As noted above, participants were only included in this study if parents reported that their child had a diagnosis of autism and their score on the SCQ was 15 or above.

\section{Types of School Non-Attendance}

Parents were asked to identify the reasons for the absences their child had during the past 20 days (4 weeks) of school using the School Non-Attendance ChecKlist (SNACK; Heyne et al., 2019). The SNACK was modified to ask parents about both full days and half days missed. Parents were first asked the number of full and half days their child had been absent from school in the past 4 weeks (20 school days). They were then presented with 14 different reasons for absence (e.g., "My child was sick [e.g., had a cold, flu, asthma], or was in hospital") and asked to identify the number of full days and half days that their child had missed school due to this reason. Parents were asked to specify only the main reason for each absence (e.g., if the child was sick so they chose to keep them home, parents were to mark the absence under "my child was sick" and not also under the "I or my partner gave the child a day off"). Parents were also prompted to check that the combined number of full and half days recorded on the SNACK items matched the number of 
missed full/half days given in the opening question, and that the number of reasons given for absences did not exceed 20. Item 15 of the SNACK is an "other" reason, where parents are able to enter a written description of the reason for the absence; using the guide developed for previous studies (e.g., Totsika et al., 2020), these were analysed to see if they could be recoded into any of the other SNACK reasons.

The reasons for school non-attendance were combined into the categories suggested by Heyne et al. (2019); nonproblematic absenteeism (NPA; SNACK reasons 1, 2, 8, 9, 10, 11, 14), school refusal (SNACK reason 3), truancy (SNACK reason 4), school withdrawal (i.e. absences when the parent decides to keeps the young person at home or when they make little or no attempt to get the young person to school; SNACK reasons 5, 6, 7), and school exclusion (i.e. absenteeism based on school-based decision-making which includes exclusions but also when the school is unable or unwilling to accommodate the needs of the student; SNACK reasons 12,13). Detailed definitions of each category and what it does and does not include are provided in Heyne et al. (2019)

\section{Child Anxiety}

The Anxiety Scale for Children - Autism Spectrum Disorder Parent Form (ASC-ASD-P; Rodgers et al., 2016) is a 24-item questionnaire designed to measure both the Diagnostic and Statistical Manual of Mental Disorders (DSM-5) consistent and autism-specific signs of anxiety. It has good validity, reliability, and internal consistency including good concurrent reliability with robust measures of anxiety in the general population (den Houting et al., 2018; Rodgers et al., 2016). In the current sample, Cronbach's alpha for the total score was 0.90 .

\section{Parent Depression, Anxiety, and Stress}

Parents rated the 21 items from the Depression Anxiety Stress Scale (DASS-21; Lovibond \& Lovibond, 2007), a widely used self-report measure of psychological wellbeing in parents of children on the autism spectrum (e.g., Falk et al., 2014). The measure has subscales measuring Depression, Anxiety and Stress, each consisting of seven items which are rated from 0 "did not apply to me at all" to 3 "applied to me very much or most of the time". Each subscale score is calculated by summing the scores for the relevant items, with subscale scores ranging from 0 to 21 . The DASS-21 questionnaire can be downloaded from the DASS website (http://www.psy.unsw.edu.au/dass/). All three subscales demonstrated good internal consistency in this study (Depression $\alpha=0.88$, Anxiety $\alpha=0.78$, Stress $\alpha=0.85$ ).

\section{Data Analysis}

As the only previous study to use the SNACK in children on the autism spectrum found no difference in predictors between total frequency of non-attendance, persistent absence, and one or more days absent, the independent variables used throughout this study are the number of full days and number of half days absent from school. The frequency of each type of school non-attendance (half or full day) was reported using descriptive statistics (mean with standard deviation as well as median with range). Individual reasons for non-attendance were summed into the SNACK subscales as described in the Method, and the descriptive statistics repeated.

As the independent variable selected is count data with an uneven variance and mean, multivariate negative binomial regression models with loglink were used. Model fit was assessed using Chi-Square goodness of fit tests alongside plots of standardised deviance residuals. Aligning with common practice for binomial regression and in concordance with the previous study reporting upon the SNACK in students on the autism spectrum, exponential estimates are interpreted as relative risks (RRs). RRs are reported with 95\% confidence intervals; RRs that do not cross 1 indicate a statistically significant RR. As noted in Totsika et al. (2020), RRs cannot be used to infer the magnitude of risk, but instead indicate the magnitude of the association (i.e., the effect size). As the regressions used are multivariate, the RRs reported are in the context of accounting for the effect of the other potential covariates.

The first stage of the analysis aimed to explore whether the factors identified as significant predictors in Totsika et al.'s (2020) models that were also collected as part of the current study (child age, parental employment, and school setting) are significant predictors of school non-attendance in this sample. These dependent variables were entered into the regression with the number of full days absent across the 20-day period entered as the independent variable. Then, to identify whether parent and child mental health are significant covariates of school non-attendance, either independently of or in combination with the factors previously shown to be significant predictors, the regression was repeated with the independent variables of child age, parental employment, school setting, child anxiety, parent anxiety, parent depression, and parent stress and the dependent variable of number of full days absent. The same process was then completed with the dependent variable of number of half days absent. Finally, to explore whether specific covariates predict subtypes of school non-attendance, the analysis was then repeated with each SNACK subscale that had more than $30 \%$ of the sample recording at least one absence due to this reason. This minimum number was decided a priori in order to allow for a large enough distribution of scores 
above 0 (i.e., $>n=30$ ) to conform to the negative binomial distribution.

\section{Results}

\section{Prevalence and Types of School Non-Attendance}

Table 2 documents the number of days on average that the children were absent from school in a 4-week (20-schoolday) period. On average, children missed 6.3 full days ( $S D$ 5.3) and 3.8 half days of school within the 20-day period. Of the six children who were absent from school for the entire 4 weeks, four were absent on all 20 days due to school refusal, one was absent for 18 days due to school refusal and two days due to illness, the final child was absent for 8 days due to school refusal and the other days due to a variety of reasons. Persistent absence ( 3 or more days in the 20-day period, for any reason) was present in $72.6 \%$ of responders.

School reluctance/refusal was responsible for the highest number of half and full days missed in total, accounting for $57.2 \%$ of all of the full-day absences and $52.6 \%$ of all of the half-day absences reported. A little over half of the sample (54.7\%) were reported to miss at least one full school day in the past 20 school days due to school reluctance/refusal. Persistent absence due to school reluctance/refusal alone was noted in $43.4 \%$ of the sample. The most frequent reason for children missing one or more half days across the 4-week period was a medical or specialist appointment, which occurred at least once across a 4 -week period in $42.5 \%$ of the children.

\section{Child, Family, and School Factors Related to School Non-attendance}

The results of the multivariate negative binomial regression models for full-day and half-day attendances are summarised in Table 3. When the previously established predictors of child age, parental employment, and school setting were entered into the model, there was one significant correlate of both full-day and half-day absences (for any reason). This was parental employment status; when the parent reported to not be in paid employment, the risk of non-attendance increased by $80 \%$ for full-day absences (RR 1.8) and $90 \%$ for half-day absences (RR 1.9). None of the other previously established covariates were significant predictors in this sample.

The previously established predictors of child age, parental employment, and school setting were then entered into the model alongside measures of child anxiety (ASC-ASD-P total score), parental depression, stress, and anxiety (DASS subscale scores). The model for full-day absences was significant (Omnibus Likelihood Ratio Chi Square $=14.5$, $p=0.04$ ) but there were no significant covariates or factors within the model. When the model was repeated with the number of half days absent as the independent variable, parent employment (RR 2.0) and child anxiety (RR 1.03) were significant covariates. This means that the risk of half-day absences increased by $3 \%$ with higher child anxiety and by $100 \%$ if the parent was not in paid employment.

\section{Child, Family, and School Factors Related to Specific Types of Non-attendance}

Factors and covariates varied for the full-day non-problematic absences and for both full- and half-day absences due to school reluctance/refusal. The model fit was adequate for the non-problematic full-day absences but the model itself was not significant (Omnibus Likelihood Ratio Chi Square $=3.9$, $p=0.80$ ) and there were no significant covariates.

Different predictors were identified for school refusal causing a full-day absence rather than a half-day school absence. The risk of a full day of non-attendance due to school refusal increased by $20 \%$ as parental DASS depression scores increased, $10 \%$ as child age increased, $150 \%$ if the parent was not in paid employment, but decreased as parental stress increased (RR 0.9). The risk of a half day of non-attendance due to school refusal increased marginally $(1 \%)$ with higher child anxiety (ASC-ASD-P), increased by $20 \%$ as child age increased, and increased by $340 \%$ if the parent was not in paid employment. The risk of half-day school non-attendance due to school refusal decreased as parental anxiety increased (RR 0.9).

\section{Discussion}

Within the current study, children on the autism spectrum were reported to miss 6 full days of school each 4 weeks; this is the equivalent of missing almost one third of their schooling. This rate is notably higher than the 1-1.4 days of school per 4 weeks missed by the general student population (Australian Institute of Health \& Welfare, 2020; Department for Education, 2019). Regardless of the cause of non-attendance, if children on the autism spectrum are missing (on average, at least) four times more school than their peers, it is critical that future research looks at the impact that this level of non-attendance has on academic outcomes and achievement.

The most common reason reported for school absences in this sample was school refusal, which was the reason identified for $57.2 \%$ of full-day absences. A little over half of the sample $(54.7 \%)$ were reported to miss one day or more from the past 20 school days due to school reluctance/refusal. Results of multivariate negative binomial regression models provide further evidence for the importance of parental 
Table 2 Number of children with one or more absences, and the mean (SD) and median (Range) number of absences for each SNACK reason and the SNACK subscales across 20 school days

\begin{tabular}{|c|c|c|c|c|}
\hline SNACK reason for absence & & $\begin{array}{l}\text { Number }(\%) \text { of children with } \\
1+\text { occurrence }\end{array}$ & $\begin{array}{l}\text { Median (Min-Max) } \\
\text { occurrences }\end{array}$ & $\begin{array}{l}\text { Mean }(S D) \\
\text { number of occur- } \\
\text { rences }\end{array}$ \\
\hline \multirow[t]{2}{*}{ 1. Medical or specialist appointment } & Full day & $\begin{array}{l}25 \\
(23.6 \%)\end{array}$ & $\begin{array}{l}0 \\
0-4\end{array}$ & $\begin{array}{l}0.4 \\
(.90)\end{array}$ \\
\hline & Half day & $\begin{array}{l}45 \\
(42.5 \%)\end{array}$ & $\begin{array}{l}0 \\
0-7\end{array}$ & $\begin{array}{l}1.0 \\
(1.5)\end{array}$ \\
\hline \multirow[t]{2}{*}{ 2. Child unwell } & Full day & $\begin{array}{l}35 \\
(33 \%)\end{array}$ & $\begin{array}{l}0 \\
0-7\end{array}$ & $\begin{array}{l}0.9 \\
(1.8)\end{array}$ \\
\hline & Half day & $\begin{array}{l}7 \\
(6.6 \%)\end{array}$ & $\begin{array}{l}0 \\
0-3\end{array}$ & $\begin{array}{l}0.1 \\
(0.4)\end{array}$ \\
\hline \multirow[t]{2}{*}{ 3. School refusal or reluctance } & Full day & $\begin{array}{l}58 \\
(54.7 \%)\end{array}$ & $\begin{array}{l}1 \\
0-20\end{array}$ & $\begin{array}{l}3.7 \\
(5.2)\end{array}$ \\
\hline & Half day & $\begin{array}{l}33 \\
(31.1 \%)\end{array}$ & $\begin{array}{l}0 \\
0-16\end{array}$ & $\begin{array}{l}2.0 \\
(4.1)\end{array}$ \\
\hline \multirow[t]{2}{*}{ 4. Truancy } & Full day & 0 & 0 & 0 \\
\hline & Half day & $\begin{array}{l}2 \\
(1.9 \%)\end{array}$ & $\begin{array}{l}0 \\
0-3\end{array}$ & $\begin{array}{l}0.1 \\
(0.4)\end{array}$ \\
\hline \multirow[t]{2}{*}{ 5. Parent gave child day off } & Full day & $\begin{array}{l}16 \\
(15.1 \%)\end{array}$ & $\begin{array}{l}0 \\
0-20\end{array}$ & $\begin{array}{l}0.4 \\
(2.0)\end{array}$ \\
\hline & Half day & $\begin{array}{l}5 \\
(4.7 \%)\end{array}$ & $\begin{array}{l}0 \\
0-4\end{array}$ & $\begin{array}{l}0.1 \\
(0.5)\end{array}$ \\
\hline \multirow[t]{2}{*}{ 6. Parent kept child at home } & Full day & $\begin{array}{l}10 \\
(9.4 \%)\end{array}$ & $\begin{array}{l}0 \\
0-2\end{array}$ & $\begin{array}{l}0.1 \\
(0.3)\end{array}$ \\
\hline & Half day & $\begin{array}{l}1 \\
(0.9 \%)\end{array}$ & $\begin{array}{l}0 \\
0-2\end{array}$ & $\begin{array}{l}0.02 \\
(0.2)\end{array}$ \\
\hline \multirow[t]{2}{*}{ 7. Parent arranged extra holidays } & Full day & $\begin{array}{l}4 \\
(3.8 \%)\end{array}$ & $\begin{array}{l}0 \\
0-12\end{array}$ & $\begin{array}{l}0.2 \\
(1.2)\end{array}$ \\
\hline & Half day & 0 & 0 & 0 \\
\hline \multirow[t]{2}{*}{ 8. Family urgent situation } & Full day & $\begin{array}{l}2 \\
(1.9 \%)\end{array}$ & $\begin{array}{l}0 \\
0-5\end{array}$ & $\begin{array}{l}0.06 \\
(0.5)\end{array}$ \\
\hline & Half day & $\begin{array}{l}1 \\
(0.9 \%)\end{array}$ & $\begin{array}{l}0 \\
0-1\end{array}$ & $\begin{array}{l}0.01 \\
(1.0)\end{array}$ \\
\hline \multirow[t]{2}{*}{ 9. Family difficulties } & Full day & $\begin{array}{l}2 \\
(1.9 \%)\end{array}$ & $\begin{array}{l}0 \\
0-1\end{array}$ & $\begin{array}{l}0.02 \\
(0.1)\end{array}$ \\
\hline & Half day & $\begin{array}{l}3 \\
(2.8 \%)\end{array}$ & $\begin{array}{l}0 \\
0-2\end{array}$ & $\begin{array}{l}0.04 \\
(0.2)\end{array}$ \\
\hline \multirow[t]{2}{*}{ 10. Religious/ cultural observance } & Full day & 0 & 0 & 0 \\
\hline & Half day & 0 & 0 & 0 \\
\hline \multirow[t]{2}{*}{ 11. School was closed } & Full day & $\begin{array}{l}13 \\
(12.3 \%)\end{array}$ & $\begin{array}{l}0 \\
0-2\end{array}$ & $\begin{array}{l}0.2 \\
(0.5)\end{array}$ \\
\hline & Half day & 0 & 0 & 0 \\
\hline \multirow[t]{2}{*}{ 12. School sent child home } & Full day & $\begin{array}{l}10 \\
(9.4 \%)\end{array}$ & $\begin{array}{l}0 \\
0-12\end{array}$ & $\begin{array}{l}0.4 \\
(1.5)\end{array}$ \\
\hline & Half day & $\begin{array}{l}10 \\
(9.4 \%)\end{array}$ & $\begin{array}{l}0 \\
0-4\end{array}$ & $\begin{array}{l}0.2 \\
(0.6)\end{array}$ \\
\hline \multirow[t]{2}{*}{ 13. School asked child to stay home } & Full day & $\begin{array}{l}5 \\
(4.7 \%)\end{array}$ & $\begin{array}{l}0 \\
0-9\end{array}$ & $\begin{array}{l}0.12 \\
(0.8)\end{array}$ \\
\hline & Half day & $\begin{array}{l}3 \\
(2.8 \%)\end{array}$ & $\begin{array}{l}0 \\
0-20\end{array}$ & $\begin{array}{l}0.2 \\
(2.1)\end{array}$ \\
\hline \multirow[t]{2}{*}{ 14. Weather } & Full day & $\begin{array}{l}2 \\
(1.9 \%)\end{array}$ & $\begin{array}{l}0 \\
0-1\end{array}$ & $\begin{array}{l}0.02 \\
(0.1)\end{array}$ \\
\hline & Half day & 0 & 0 & 0 \\
\hline
\end{tabular}


Table 2 (continued)

\begin{tabular}{|c|c|c|c|c|}
\hline SNACK reason for absence & & $\begin{array}{l}\text { Number }(\%) \text { of children with } \\
1+\text { occurrence }\end{array}$ & $\begin{array}{l}\text { Median (Min-Max) } \\
\text { occurrences }\end{array}$ & $\begin{array}{l}\text { Mean }(S D) \\
\text { number of occur- } \\
\text { rences }\end{array}$ \\
\hline \multirow[t]{2}{*}{ Non-problematic absenteeism } & Full day & $\begin{array}{l}58 \\
(54.7 \%)\end{array}$ & $\begin{array}{l}1 \\
(0-8)\end{array}$ & $\begin{array}{l}1.6 \\
(2.1)\end{array}$ \\
\hline & Half day & $\begin{array}{l}11 \\
(10.4 \%)\end{array}$ & $\begin{array}{l}0 \\
(0-7)\end{array}$ & $\begin{array}{l}1.1 \\
(1.6)\end{array}$ \\
\hline \multirow[t]{2}{*}{ School refusal } & Full day & $\begin{array}{l}58 \\
(54.7 \%)\end{array}$ & $\begin{array}{l}1 \\
(0-20)\end{array}$ & $\begin{array}{l}3.7 \\
(5.2)\end{array}$ \\
\hline & Half day & $\begin{array}{l}33 \\
(31.1 \%)\end{array}$ & $\begin{array}{l}0 \\
(0-16)\end{array}$ & $\begin{array}{l}2.0 \\
(4.1)\end{array}$ \\
\hline \multirow[t]{2}{*}{ Truancy } & Full day & 0 & 0 & 0 \\
\hline & Half day & $\begin{array}{l}2 \\
(1.9 \%)\end{array}$ & $\begin{array}{l}0 \\
(0-3)\end{array}$ & $\begin{array}{l}0.1 \\
(0.4)\end{array}$ \\
\hline \multirow[t]{2}{*}{ School withdrawal } & Full day & $\begin{array}{l}27 \\
(25.5 \%)\end{array}$ & $\begin{array}{l}0 \\
(0-20)\end{array}$ & $\begin{array}{l}0.7 \\
(2.4)\end{array}$ \\
\hline & Half day & $\begin{array}{l}6 \\
(5.7 \%)\end{array}$ & $\begin{array}{l}0 \\
(0-4)\end{array}$ & $\begin{array}{l}0.1 \\
(0.5)\end{array}$ \\
\hline \multirow[t]{2}{*}{ School exclusion } & Full day & $\begin{array}{l}13 \\
(12.3 \%)\end{array}$ & $\begin{array}{l}0 \\
(0-12)\end{array}$ & $\begin{array}{l}0.5 \\
(1.8)\end{array}$ \\
\hline & Half day & $\begin{array}{l}11 \\
(10.4 \%)\end{array}$ & $\begin{array}{l}0 \\
(0-20)\end{array}$ & $\begin{array}{l}0.4 \\
(2.1)\end{array}$ \\
\hline
\end{tabular}

Table 3 Covariates and relative risks from the multivariate negative binomial regression models for the number of full and half days absent for any reason, number of full days absent due to non-problematic attendance, and full and half days absent due to school refusal

\begin{tabular}{|c|c|c|c|c|c|c|c|}
\hline & \multicolumn{2}{|c|}{$\begin{array}{l}\text { Number of full days absent (all } \\
\text { reasons) }\end{array}$} & \multicolumn{2}{|c|}{$\begin{array}{l}\text { Number of half days absent (all } \\
\text { reasons) }\end{array}$} & \multirow{2}{*}{$\begin{array}{l}\text { Non- } \\
\text { problematic } \\
\text { absence } \\
\text { Full day }\end{array}$} & \multicolumn{2}{|l|}{ School refusal } \\
\hline & & & & & & Full day & Half day \\
\hline Child age & $2.2(.82-5.5)$ & $1.59(44-5.87)$ & $1.1(.97-1.1)$ & $1.04(.97-1.1)$ & $1.0(0.9-1.1)$ & $1.1(1.0-1.2)^{* * *}$ & $1.2(1.0-1.3)^{* *}$ \\
\hline $\begin{array}{l}\text { Attends mainstream } \\
\text { school }\end{array}$ & $1 / 3(.69-2.2)$ & $1.15(.62-2.2)$ & $1.0(.55-1.8)$ & $.92(.47-1.8)$ & $1.1(0.5-2.5)$ & $1.4(0.7-1.9)$ & $0.8(0.3-1.6)$ \\
\hline $\begin{array}{l}\text { Parent in paid employ- } \\
\text { ment }\end{array}$ & $1.8(1.2-2.7)^{* *}$ & $1.53(.97-2.4)$ & $1.9(1.2-2.9)^{* *}$ & $2.0(1.3-3.3)^{* *}$ & $1.5(0.9-2.6)$ & $2.5(1.5-4.0)^{* * *}$ & $4.4(2.4-7.9)^{* * *}$ \\
\hline Parent depression & - & $1.08(.99-1.2)$ & - & $1.0(.93-1.1)$ & $1.0(0.9-1.1)$ & $1.2(1.0-1.3)^{* *}$ & $1.0(0.9-1.2)$ \\
\hline Parent anxiety & - & $0.98(.89-1.7)$ & - & $.91(.82-1.0)$ & $1.0(0.9-1.1)$ & $1.0(0.9-1.1)$ & $0.9(0.7-0.9)^{*}$ \\
\hline Parent stress & - & $0.97(.89-1.1)$ & - & $.99(.91-1.1)$ & $1.1(0.9-1.2)$ & $0.9(0.8-0.9)^{*}$ & $1.0(0.8-1.0)$ \\
\hline Child anxiety & - & $1.0(.99-1.0)$ & - & $1.03(1.0-1.1)^{*}$ & $1.0(1.0-1.0)$ & $1.0(0.9-1.0)$ & $1.1(1.0-1.1)^{* * *}$ \\
\hline
\end{tabular}

Bold values indicate significant results

$* p<0.5$

$* * p<.01$

$* * * p<.001$

employment status as a factor predicting the frequency of school absences but also highlight the role of child age as well as child and parental mental health as covariates in the frequency of absences due to school refusal/reluctance.

\section{Frequency and Reasons for School Non-Attendance}

Parents reported that, on average, children missed 6 full days from school in each 4-week (20-school-day) period. Ten children $(9.4 \%)$ within the sample did not miss any days, and despite being enrolled in a school, six (5.7\%) missed all 20 days. The proportion of children who missed all 20 days 
is similar between this sample $(5.7 \%)$ and that reported in Totsika et al.'s (2020) study (7\%). However, the proportion of children with full attendance in the current study (9.4\%) is notably lower than the $36 \%$ with full-time attendance in Totsika et al. This may reflect different sampling methods, with this current study recruiting online and Totsika et al. recruiting through schools. It is possible that parents of children without challenges in school attendance who saw a study exploring school non-attendance online may not have participated, or potentially it is possible that children with attendance challenges who received the information through school may not have had the time or the inclination to participate. This highlights the importance of drawing upon the data from multiple studies using varied recruitment methods.

The school non-attendance literature to date has tended to focus upon full days missed; however, any time missed from school can potentially represent missed learning opportunities, so within the current study, half-day absences were also explored. In addition to missing 6 full days of school (on average) in a 4-week period, children on the autism spectrum are also reported to miss 3.8 half days of school within the 20-day period. The most frequent reason for at least one half-day of non-attendance was medical or therapy appointments, which occurred at least once across a 4-week period in $42.5 \%$ of the children. With higher levels of physical and mental health difficulties (Fortuna et al., 2016), children on the autism spectrum have to attend more likely general practitioner or outpatient healthcare visits than their age-matched typically developing peers (Weiss et al., 2018; Zerbo et al., 2019). In addition to general healthcare needs, on average, families report using multiple interventions or therapies for their child (Thomas et al., 2007), with families reporting (on average) $3-4 \mathrm{~h}$ of therapy appointments per week for schoolaged children and adolescents (Montiel-Nava et al., 2020). With this large number of therapy appointments to schedule and the challenge of fitting appointments into a work or school schedule being identified as a barrier to accessing therapy for children on the autism spectrum (Adams $\&$ Young, 2020), it is understandable why parents have to schedule appointments so that school is missed. Children on the autism spectrum may also be at increased risk of even short healthcare appointments resulting in half- or full-day absences due to problems with transitioning into school midway through the day (once routine is disrupted) or due to the sensory or cognitive demands of the appointment itself (see review by Mason et al., 2019). Future work should therefore consider the frequency and impact of both half- and full-day absences when exploring school non-attendance in children on the autism spectrum.

The data from the current study suggest that, on average, children on the autism spectrum miss 1 day every 2 months due to school exclusion, which includes times that the child was sent home for their behaviour and times the child was asked to stay away from school as the school could not support the child's needs or keep them safe at school. Within the sample reported on in this study, twice as many children were sent home $(9.4 \%)$ for at least one full day in the 4 weeks than were asked to stay home (4.7\%). For reference, international data suggest that $4-7 \%$ of the general student population receive at least one full-day school suspension across an entire year (Green et al., 2005). This elevated rate of school suspensions or exclusions for students on the autism spectrum compared to published rates for the general student population has been noted in numerous previous studies; for example, Krezmien et al. (2017) reported odds ratios of 1.9 for school suspensions for students on the autism spectrum compared to students without a disability in 2015 . While a few studies have explored the impact of school exclusion and placement breakdown from the perspective of the individual on the autism spectrum (Brede et al., 2017; Sproston et al., 2017), there is a need for further qualitative work to explore the impact that these short-term suspensions have on children on the autism spectrum, who may by nature of their diagnosis find such additional transitions, changes to routine, and unpredictability difficult (Goris et al., 2021).

Not every form of school non-attendance measured was higher in students on the autism spectrum. As per previous studies exploring school non-attendance in students on the autism spectrum, truancy was almost non-existent; no children were reported to show truancy resulting in full days missed and only two children were reported to be truant for half-days, whereas general student population estimates suggest that $4-11 \%$ of children miss at least one full day of school per month due to truancy (Vaughn et al., 2013).

\section{Covariates and Factors Predictive of the Frequency of Full- and Half-Days of School Non-Attendance}

The initial multivariate negative binomial regression models aimed to explore whether factors that were predictive of school non-attendance frequency in Totsika et al. (2020) were also predictive of school non-attendance frequency in this sample. Only parental employment status was a significant covariate of the number of full-day and half-day absences. The relative risk (RR) ratios highlight that the risk of non-attendance (for any reason) increased by $80 \%$ for full-day absences (RR 1.8) and by $90 \%$ for half-day absences (RR 1.9) when the parent stated that they were not in paid employment. Of course, as the study is cross-sectional, the directionality of this cannot be inferred; it may be that the parent chose not to be, or could not be, in paid employment due to their child's non-attendance. Longitudinal work is needed in order to document the potentially interacting pathways of emerging or early non-attendance and parental employment status. Although child age and school type were significant predictors in Totsika et al., they were not 
significant covariates of overall full-day or half-day absences in this sample.

The second stage of the negative binomial regression models included measures of child anxiety and parental anxiety, depression and stress, and other "out of school" factors which may influence school attendance. This is the first study, to the author's knowledge, to explore the role of parental and child mental health in school non-attendance in students on the autism spectrum. When these additional variables were included in the model for the number of full-day absences, there were no significant covariates in the model. However, parent employment status remained a significant predictor, but also child anxiety was a significant covariate of half-day absences. The small but significant increase in risk of half-day absences with increasing child anxiety highlights the importance of considering mental health when exploring school attendance. Discussed further below, anxiety is one of the most commonly co-occurring conditions in individuals on the autism spectrum, with approximately $40 \%$ of children receiving a clinical diagnosis of an anxiety disorder (van Steensel et al., 2011) and up to another $40 \%$ impacted by "subclinical" anxiety symptoms (Adams et al., 2019a, 2019b, 2019d). However, the predominant focus of the anxiety in autism research has been upon symptomatology, with few studies exploring the impact of the anxiety, for example, on academic outcomes or school attendance (Adams \& Emerson, 2020b). This finding that child anxiety increases the risk of half-day school absences suggests that further work is needed to understand the impact of anxiety in autism at school and how it may contribute to these absences.

\section{Covariates and Factors Predictive of the Frequency of Specific Types of School Non-Attendance}

The multivariate negative binomial regression models explored the predictive factors and covariates of specific absence types, specifically the non-problematic full-day absences and both full- and half-day absences due to school reluctance/refusal. The focus was on these subtypes of school non-attendance as at least $30 \%$ of the sample reported at least one absence for these reasons, thereby allowing a sample of more than 30 participants with count data in excess of one.

The model for non-problematic full-day absences due to medical appointments was not significant, indicating that the model which included the covariates did not explain more than the model with the intercept alone. This suggests that absences due to reasons such as medical or therapy appointments, school closures, or family emergencies may result in missed school days across children on the autism spectrum of all ages, attending mainstream and specialist/special schools, and not predicted by parental education, parental mental health, or child anxiety.

The predictors and covariates differed between school refusal/reluctance resulting in a full-day absence and that resulting in a half-day school absence. For the full-day absence, child age, parental employment status, parental depression, and parental stress were all significant predictors; however, while the risk increased as the child got older, if the child was in mainstream schooling and with increasing parental depression, it decreased with parental stress. The presence of child-, family-, and school-related factors aligns with the KiTeS model proposed by Melvin et al. (2019) but may also go some way to explain why (at least in the general student population) parents and students tend to identify school-related factors as the main driver for non-attendance while school staff tend to identify parental attitudes and the home environment as more influential (e.g., Gren-Landell et al., 2015). Parental depression has been associated with school attendance in the general student population (RR 1.4; Guevara et al., 2013) as well as in children with chronic health problems (Rodriguez et al., 2017). Parental stress has not been extensively explored in relation to school refusal, but it may be that higher stress in conjunction with lower depression and paid employment is associated with a decreased risk of school attendance as parents have less emotional or practical resources to allow their child to be home on days of school refusal. However, this very tentative hypothesis needs exploring through larger quantitative and in-depth qualitative studies which specifically look at the impact of parenting and parental psychopathology on school refusal in children on the autism spectrum.

Interestingly, two of the four factors associated with an increased risk of half-day non-attendance due to school refusal were the same as those for full-day absences due to school refusal (increasing child age, parent employment status) and two differed. This may suggest that some factors are more important in early, or emerging school refusal (i.e., when it only results in half days missed) and others become more influential as the school refusal becomes more established and results in full-day absences (see Kearney, 2008, for a continuum of school refusal behaviours). Within the typically developing school refusal literature, anxiety has been associated with some reasons for school non-attendance. A recent meta-analysis identified little association between anxiety and absences due to medical appointments/ illness or truancy, but strong cross-sectional evidence for a positive association between anxiety (social anxiety, generalised anxiety, simple phobias) and school absences due to school refusal (Finning et al., 2019). Further evidence for the role of anxiety in school refusal is through the effectiveness of interventions for school refusal which purposefully address the child's anxiety relating to school attendance (see review by Elliott \& Place, 2019). 
Given the elevated prevalence of anxiety in autism (van Steensel et al., 2011) and its increasingly recognised impact on school outcomes (Adams \& Emerson, 2020b; den Houting et al., 2020), it is unsurprising that anxiety is a significant covariate of the risk of half-day school refusal, albeit a very modest one. Future studies with larger samples (which could then include more variables into the regression) could explore whether specific aspects of anxiety, such as difficulties with uncertainty, are more strongly associated with school refusal than others. This would then help to inform intervention, and whether such intervention needs to be tailored to specific risk factors for school refusal in children on the autism spectrum. The finding that anxiety is no longer a significant covariant in full-day school refusal highlights the importance of cognitive-behavioural interventions as early prevention or intervention for school refusal, before it leads to full-day absences.

\section{Limitations and Future Directions}

This study, as with all studies, should be considered in the context of its limitations. Firstly, the study would be strengthened by having data from schools to validate the frequency of absences reported by parents. Providing parents with a clear definition of what is defined as a half-day absence and exploring the prevalence of tardiness/late entry into school would strengthen and expand any future studies into this area.

An a priori decision to only including data on children aged up to 17 who, in addition to parent-reported diagnosis of autism, had an SCQ score above the established cut-off of 15 was taken to increase the validity of the sample characteristics. However, this may have resulted in the exclusion of some participants or groups of participants who may have differing or specific attendance patterns to explore.

There is a clear need for large, longitudinal studies which can identify the pathway from attendance to absence and identify the factors predictive of this. Having larger samples would also allow for the exploration of factors predictive of some of the less common absence types (e.g. school exclusions) which were only reported in 5-10 participants in this sample. Where the models were significant with no significant correlates (i.e. full days of school refusal) or nonsignificant (i.e. non-problematic attendances), this suggests that further work is needed to identify which factors might elevate the risk for these types of absences. This and other recent work (e.g. Adams et al., 2021) highlights that school non-attendances may be related to factors not identified in typically developing children and that these factors need to explored within future research.

To develop a more comprehensive understanding of the factors influencing school non-attendance, additional studies including the perspectives of children on autism spectrum and their teachers are needed.

It is hoped that this study and the increasing research into school non-attendance in autism leads into a greater recognition of the scale of the issue and the understanding that some factors which are amenable to intervention (e.g. child anxiety) may be potential pathways to preventing onset and/or reducing the duration of specific forms of school absences. Increasing attendance can provide additional learning and social opportunities for students on the autism spectrum which may then, at least in part, contribute to addressing the reported academic underachievement consistently documented for students on the autism spectrum.

Acknowledgments The author is grateful to the community groups who discussed their challenges with us, their real world experiences and questions inspired this study. The author would also like to thank all of the children on the autism spectrum and their families for giving their time to support this research study.

Author contributions DA conceived the study, participated in its design and coordination, coordinated the data cleaning, performed the statistical analysis and interpretation of the data and drafted the manuscript.

Funding There is no external funding associated with this research. This work has not been presented at any conference or meeting nor posted on any website, forum, or discussion board. This research received no specific grant from any external funding agency in the public, commercial, or not-for-profit sectors.

\section{Declarations}

Conflict of interest Dawn Adams declares that she has no conflict of interest with respect to this publication.

\section{References}

Adams, D., Clark, M., \& Keen, D. (2019a). Using self-report to explore the relationship between anxiety and quality of life in children on the autism spectrum. Autism Research, 12(10), 1505-1515. https://doi.org/10.1002/aur.2155

Adams, D., Clark, M., \& Simpson, K. (2019b). The relationship between child anxiety and the quality of life of children, and parents of children, on the autism spectrum. Journal of Autism and Developmental Disorders. https://doi.org/10.1007/ s10803-019-03932-2

Adams, D., \& Emerson, L. (2020a). Family accommodation of anxiety in a community sample of children on the autism spectrum. Journal of Anxiety Disorders, 70, 102192. https://doi.org/10.1016/j. janxdis.2020.102192

Adams, D., \& Emerson, L. (2020b). The impact of anxiety in children on the autism spectrum. Journal of Autism and Developmental Disorders. https://doi.org/10.1007/s10803-020-04673-3

Adams, D., McLucas, R., Mitchelson, H., Simpson, K., \& Dargue, N. (2021). Form function and feedback on the school refusal assessment scale-revised in children on the autism spectrum. Journal of Autism and Developmental Disorders. https://doi.org/10.1007/ s10803-021-05107-4 
Adams, D., Simpson, K., \& Keen, D. (2018). School-related anxiety symptomatology in a community sample of primary-school-aged children on the autism spectrum. Journal of School Psychology, 70, 64-73. https://doi.org/10.1016/j.jsp.2018.07.003

Adams, D., \& Young, K. (2020). A systematic review of the perceived barriers and facilitators to accessing psychological treatment for mental health problems in individuals on the autism spectrum. Review Journal of Autism and Developmental Disorders. https:// doi.org/10.1007/s40489-020-00226-7

Adams, D., Young, K., \& Keen, D. (2019c). Anxiety in children with autism at school: A systematic review. Review Journal of Autism and Developmental Disorders, 6(3), 274-288. https://doi.org/10. 1007/s40489-019-00172-z

Adams, D., Young, K., Simpson, K., \& Keen, D. (2019d). Parent descriptions of the presentation and management of anxiousness in children on the autism spectrum. Autism, 23(4), 980-992. https://doi.org/10.1177/1362361318794031

Australian Institute of Health and Welfare. (2020) Australia's Children (Cat. no. CWS 69). AIHW Doi: https://doi.org/10.25816/5ebca $4 \mathrm{~d} 0 \mathrm{fa} 7 \mathrm{dd}$

Bitsika, V., Heyne, D. A., \& Sharpley, C. F. (2020). Is bullying associated with emerging school refusal in autistic boys? Journal of Autism and Developmental Disorders. https://doi.org/10.1007/ s10803-020-04610-4

Brede, J., Remington, A., Kenny, L., Warren, K., \& Pellicano, E. (2017). Excluded from school: Autistic students' experiences of school exclusion and subsequent re-integration into school. Autism \& Developmental Language Impairments, 2, 1-20. https://doi.org/ 10.1177/2396941517737511

Chesnut, S. R., Wei, T. L., Barnard-Brak, L., \& Richman, D. M. (2017). A meta-analysis of the social communication questionnaire: Screening for autism spectrum disorder. Autism, 21(8), 920-928. https://doi.org/10.1177/1362361316660065

Da Paz, N. S., \& Wallander, J. L. (2017). Interventions that target improvements in mental health for parents of children with autism spectrum disorders: A narrative review. Clinical Psychology Review, 51, 1-14. https://doi.org/10.1016/j.cpr.2016.10.006

den Houting, J., Adams, D., Roberts, J., \& Keen, D. (2018). Exploring anxiety symptomatology in school-aged autistic children using an autism-specific assessment. Research in Autism Spectrum Disorders, 50, 73-82. https://doi.org/10.1016/j.rasd.2018.03.005

den Houting, J., Adams, D., Roberts, J., \& Keen, D. (2020). Brief Report: Investigating the impact of anxious symptomatology in autistic children. International Journal of Disability, Development and Education, . https://doi.org/10.1080/1034912X.2020.1727420

Department for Education, UK. (2019). Pupil absence in schools in England: 2017 to 2018 [National statistics]. Retrieved 1st March 2021 from https://www.gov.uk/government/statistics/pupil-absen ce-in-schools-in-england-2017-to-2018

Egger, H. L., Costello, E. J., \& Angold, A. (2003). School refusal and psychiatric disorders: A community study. Journal of the American Academy of Child and Adolescent Psychiatry, 42(7), 797-807. https://doi.org/10.1097/01.Chi.0000046865.56865.79

Elliott, J. G., \& Place, M. (2019). Practitioner review: School refusal: Developments in conceptualisation and treatment since 2000. Journal of Child Psychology and Psychiatry, 60(1), 4-15. https:// doi.org/10.1111/jcpp.12848

Falk, N. H., Norris, K., \& Quinn, M. G. (2014). The factors predicting stress, anxiety and depression in the parents of children with autism. Journal of Autism and Developmental Disorders, 44(12), 3185-3203. https://doi.org/10.1007/s10803-014-2189-4

Filippello, P., Buzzai, C., Costa, S., \& Sorrenti, L. (2019). School refusal and absenteeism: Perception of teacher behaviors, psychological basic needs, and academic achievement. Frontiers in Psychology. https://doi.org/10.3389/fpsyg.2019.01471
Finning, K., Ukoumunne, O. C., Ford, T., Danielson-Waters, E., Shaw, L., Romero De Jager, I., Stentiford, L., \& Moore, D. A. (2019). The association between anxiety and poor attendance at school-A systematic review. Child and Adolescent Mental Health, 24(3), 205-216. https://doi.org/10.1111/camh.12322

Fortuna, R. J., Robinson, L., Smith, T. H., Meccarello, J., Bullen, B., Nobis, K., \& Davidson, P. W. (2016). Health conditions and functional status in adults with autism: A cross-sectional evaluation. Journal of General Internal Medicine, 31(1), 77-84. https://doi. org/10.1007/s11606-015-3509-x

Goris, J., Silvetti, M., Verguts, T., Wiersema, J. R., Brass, M., \& Braem, S. (2021). Autistic traits are related to worse performance in a volatile reward learning task despite adaptive learning rates. Autism, 25(2), 440-451. https://doi.org/10.1177/1362361320 962237

Green, H., McGinnity, Á., Meltzer, H., Ford, T., \& Goodman, R. (2005). Mental health of children and young people in Great Britain, 2004. Pan MacMillan.

Gren-Landell, M., Allvin, C. E., Bradley, M., Andersson, M., \& Andersson, G. (2015). Teachers' views on risk factors for problematic school absenteeism in Swedish primary school students. Educational Psychology in Practice, 31(4), 412-423. https://doi. org/10.1080/02667363.2015.1086726

Gubbels, J., van der Put, C. E., \& Assink, M. (2019). Risk factors for school absenteeism and dropout: A meta-analytic review. Journal of Youth and Adolescence, 48(9), 1637-1667. https://doi.org/10. 1007/s10964-019-01072-5

Guevara, J. P., Mandell, D., Danagoulian, S., Reyner, J., \& Pati, S. (2013). Parental depressive symptoms and children's school attendance and emergency department use: A nationally representative study. Maternal and Child Health Journal, 17(6), 11301137. https://doi.org/10.1007/s10995-012-1109-5

Heyne, D., Gren-Landell, M., Melvin, G., \& Gentle-Genitty, C. (2019). Differentiation between school attendance problems: Why and how? Cognitive and Behavioral Practice, 26(1), 8-34. https://doi. org/10.1016/j.cbpra.2018.03.006

Ingul, J. M., Havik, T., \& Heyne, D. (2019). Emerging school refusal: A school-based framework for identifying early signs and risk factors. Cognitive and Behavioral Practice, 26(1), 46-62. https:// doi.org/10.1016/j.cbpra.2018.03.005

John, T. S., Dawson, G., \& Estes, A. (2018). Brief report: Executive function as a predictor of academic achievement in school-aged children with ASD. Journal of Autism and Developmental Disorders, 48(1), 276-283. https://doi.org/10.1007/s10803-017-3296-9

Kearney, C. A. (2008). School absenteeism and school refusal behavior in youth: A contemporary review. Clinical Psychology Review, 28(3), 451-471. https://doi.org/10.1016/j.cpr.2007.07.012

Keen, D., Webster, A., \& Ridley, G. (2016). How well are children with autism spectrum disorder doing academically at school? An Overview of the Literature. Autism, 20(3), 276-294. https://doi. org/10.1177/1362361315580962

Keen, D., Adams, D., \& Simpson, K. (2021). Teacher ratings of academic skills and academic enablers of children on the autism spectrum. International Journal of Inclusive Education. https:// doi.org/10.1080/13603116.2021.1881626

Krezmien, M. P., Travers, J. C., \& Camacho, K. (2017). Suspension rates of students with autism or intellectual disabilities in Maryland from 2004 to 2015. Journal of Intellectual Disability Research, 61(11), 1011-1020. https://doi.org/10.1111/jir.12406

Lovibond, P. F., \& Lovibond, S. H. (2007). The structure of negative emotional states: comparison of the depression anxiety stress scales (DASS) with the beck depression and anxiety inventories. Behaviour Research and Therapy, 33, 335-343. https://doi.org/ 10.1016/0005-7967(94)00075-U 
Mason, D., Ingham, B., Urbanowicz, A., Michael, C., Birtles, H., Woodbury-Smith, M., Brown, T., James, I., Scarlett, C., Nicolaidis, C., \& Parr, J. R. (2019). A systematic review of what barriers and facilitators prevent and enable physical healthcare services access for autistic adults. Journal of Autism and Developmental Disorders, 49(8), 3387-3400. https://doi.org/10.1007/ s10803-019-04049-2

Mayes, S. D., Waschbusch, D. A., Calhoun, S. L., \& Mattison, R. E. (2020). Correlates of academic overachievement, nondiscrepant achievement, and learning disability in ADHD, autism, and general population samples. Exceptionality, 28(1), 60-75. https://doi. org/10.1080/09362835.2020.1727324

McClemont, A. J., Morton, H. E., Gillis, J. M., \& Romanczyk, R. G. (2020). Brief report: Predictors of school refusal due to bullying in children with autism spectrum disorder and attention-deficit/ hyperactivity disorder. Journal of Autism and Developmental Disorders. https://doi.org/10.1007/s10803-020-04640-y

Melvin, G. A., Heyne, D., Gray, K. M., Hastings, R. P., Totsika, V., Tonge, B. J., \& Freeman, M. (2019). The Kids and Teens at School (KiTeS) framework: An inclusive bioecological systems approach to understanding school absenteeism and school attendance problems [Conceptual Analysis]. Frontiers in Education. https://doi.org/10.3389/feduc.2019.00061

Milgramm, A., Christodulu, K. V., \& Rinaldi, M. L. (2021). Brief report: predictors of teacher-rated academic competence in a clinic sample of children with and without autism spectrum disorder. Journal of Autism and Developmental Disorders, 51, 2132-2138. https://doi.org/10.1007/s10803-020-04680-4

Montiel-Nava, C., Cukier, S., Garrido, G., Valdez, D., Paula, C. S., Garcia, R., Rosoli, A., Irarrazaval, M., \& Rattazzi, A. (2020). Service encounters across the lifespan in individuals with autism spectrum disorders: Results from a multisite study in Latin America. Research in Autism Spectrum Disorders. https://doi.org/10. 1016/j.rasd.2020.101670

Munkhaugen, E. K., Torske, T., Gjevik, E., Naerland, T., Pripp, A. H., \& Diseth, T. H. (2019). Individual characteristics of students with autism spectrum disorders and school refusal behavior. Autism, 23(2), 413-423. https://doi.org/10.1177/1362361317748619

Ochi, M., Kawabe, K., Ochi, S., Miyama, T., Horiuchi, F., \& Ueno, S. I. (2020). School refusal and bullying in children with autism spectrum disorder. Child and Adolescent Psychiatry and Mental Health, 14, 17. https://doi.org/10.1186/s13034-020-00325-7

Perihan, C., Burke, M., Bowman-Perrott, L., Bicer, A., Gallup, J., Thompson, J., \& Sallese, M. (2020). Effects of cognitive behavioral therapy for reducing anxiety in children with high functioning ASD: A systematic review and meta-analysis. Journal of Autism and Developmental Disorders, 50(6), 1958-1972. https://doi.org/ 10.1007/s10803-019-03949-7

Rodgers, J., Wigham, S., McConachie, H., Freeston, M., Honey, E., \& Parr, J. R. (2016). Development of the anxiety scale for children with autism spectrum disorder (ASC-ASD). Autism Research, 9(11), 1205-1215. https://doi.org/10.1002/aur.1603

Rodriguez, E. M., Kumar, H., Alba-Suarez, J., \& Sanchez-Johnsen, L. (2017). Parental coping, depressive symptoms, and children's asthma control and school attendance in low-income, racially, and ethnically diverse urban families. Journal of Asthma, 54(8), 833-841. https://doi.org/10.1080/02770903.2016.1274402

Rutter, M., Bailey, A., \& Lord, C. (2003). Social Communication Questionnaire. Western Psychological Services.

Sproston, K., Sedgewick, F., \& Crane, L. (2017). Autistic girls and school exclusion: Perspectives of students and their parents. Autism \& Developmental Language Impairments, 2, 1-14. https:// doi.org/10.1177/2396941517706172

Thomas, K. C., Ellis, A. R., McLaurin, C., Daniels, J., \& Morrissey, J. P. (2007). Access to care for autism-related services. Journal of Autism and Developmental Disorders, 37(10), 1902-1912. https:// doi.org/10.1007/s10803-006-0323-7

Totsika, V., Hastings, R. P., Dutton, Y., Worsley, A., Melvin, G., Gray, K., Tongue, B., \& Heyne, D. A. (2020). Types and correlates of school non-attendance in students with autism spectrum disorders. Autism, 24(7), 1639-1649. https://doi.org/10.1177/1362361320 916967

van Steensel, F. J. A., Bogels, S. M., \& Perrin, S. (2011). Anxiety disorders in children and adolescents with autistic spectrum disorders: A meta-analysis. Clinical Child and Family Psychology Review, 14(3), 302-317. https://doi.org/10.1007/s10567-011-0097-0

Vaughn, M. G., Maynard, B. R., Salas-Wright, C. P., Perron, B. E., \& Abdon, A. (2013). Prevalence and correlates of truancy in the US: Results from a national sample. Journal of Adolescence, 36(4), 767-776. https://doi.org/10.1016/j.adolescence.2013.03.015

Weiss, J. A., Isaacs, B., Diepstra, H., Wilton, A. S., Brown, H. K., McGarry, C., \& Lunsky, Y. (2018). Health concerns and health service utilization in a population cohort of young adults with autism spectrum disorder. Journal of Autism and Developmental Disorders, 48(1), 36-44. https://doi.org/10.1007/ s10803-017-3292-0

Zerbo, O., Qian, Y., Ray, T., Sidney, S., Rich, S., Massolo, M., \& Croen, L. A. (2019). Health care service utilization and cost among adults with autism spectrum disorders in a US integrated health care system. Autism in Adulthood, 1(1), 27-36. https://doi. org/10.1089/aut.2018.0004

Publisher's Note Springer Nature remains neutral with regard to jurisdictional claims in published maps and institutional affiliations. 